To Maega $\mid$ Jurnal Pengabdian Masyarakat

Februari 2021, Vol.4, No.1, hal, 90-99

$\operatorname{ISSN}(P): 2622-6332 ; \operatorname{ISSN}(E): 2622-6340$

http://www.ojs.unanda.ac.id/index.php/tomaega

\title{
Pelatihan Implementasi Alat Ukur Hemoglobin Non-Invasif (HbEy) di Palang Merah Indonesia (PMI) Kabupaten Indramayu
}

\author{
Hilman Fauzi TSP 1, Rustam ${ }^{1,}$, Yulinda Eliskar ${ }^{1}$ \\ ${ }^{1}$ Jurusan Teknik Telekomunikasi, Fakultas Teknik Elektro, Universitas Telkom \\ *Correspondent Email: rustam@telkomuniversity.ac.id
}

Article History:

Received: 02-12-2020; Received in Revised: 16-12-2020; Accepted: 23-12-2020

DOI: http://dx.doi.org/10.35914/tomaega.v4i1.531

\begin{abstract}
Abstrak
HbEY merupakan salah satu produk hasil riset tim dosen dari Kelompok Keahlian Pengolahan Sinyal Informasi (KK PSI) Telkom University. Aplikasi ini berfungsi untuk mengukur kadar hemoglobin darah secara non-invasif. HbEY memiliki kelebihan yaitu mudah dan nyaman untuk digunakan, serta harga yang terjangkau jika dibandingkan dengan alat yang saat ini banyak digunakan di instansi pemerintahan, salah satunya di Palang Merah Indonesia (PMI). Kenyamanan dan kemudahan penggunaan HbEy berdasarkan pada fakta bahwa HbEy mengukur hemoglobin (Hb) darah secara noninvasif dengan hanya melakukan instalasi aplikasi smartphone android. Pada kegiatan pengabdian masyarakat ini, sosialisasi dan implementasi aplikasi HbEY dilakukan pada masyarakat, pengurus, dan volunteer PMI Kabupaten Indramayu. Hasil dari kegiatan ini menunjukkan aplikasi HbEY dapat menjadi salah satu alternatif alat ukur kadar Hb noninvasif yang dengan mudah, murah, dan nyaman untuk digunakan. Senada dengan itu, HbEy mampu untuk menyajikan informasi terkait kadar normal atau anemia calon pendonor. Sehingga HbEy bisa menjadi acuan awal untuk mengambil keputusan apakah calon pendonor layak atau tidak.
\end{abstract}

Kata Kunci: HbEY, Produk Riset, Hemoglobin, PMI Kabupaten Indramayu

\begin{abstract}
$H b E Y$ is one of the products of research by a team of lecturers from the Information Signal Processing Research Group, Telkom University. This application serves to measure blood hemoglobin levels non-invasively. HbEY has the advantages of being easy and comfortable to use, and an affordable price when compared to tools that are currently widely used in government agencies like Indonesian Red Cross. The convenience and ease of use of HbEy are based on the fact that HbEy measures blood hemoglobin (Hb) non-invasively only by installing an android smartphone application. In this community service activity, socialization and implementation of the HbEY application were carried out to the community, administrators, and PMI Indramayu Regency volunteers. The results show that $H b E Y$ can be an alternative non-invasive $H b$ measurement tool that is easy, cheap, and comfortable to use. Likewise, HbEy is able to present information related to normal or anemia levels of prospective donors. So that HbEy can be an initial reference for making decisions regarding whether prospective donors are eligible to donate blood or not.
\end{abstract}

Keywords: HbEy, Research Product, Hemoglobin, PMI Indramayu Regency

(C)To Maega / Jurnal Pengabdian Masyarakat. This is an open access article under the CC BY-SA 4.0 license (https://creativecommons.org/licenses/by-sa/4.0/). 

2021

\section{Pendahuluan}

Salah satu kegiatan atau aktivitas utama PMI Kabupaten Indramayu yaitu donor darah. Dalam pelaksanaannya, dibutuhkan berbagai peralatan penunjang yang modern dan mahal, salah satunya adalah alat pengukur kadar hemoglobin. Alat ukur yang digunakan saat ini adalah alat analisis digital dan analisis laboratorium yang keduanya melalui proses pengambilan darah secara invasif seperti yang ditunjukkan pada Gambar 1. Metode ini dinilai tidak murah dan tidak nyaman bagi pendonor. Ketidaknyamaanan metode invasif berdasarkan pada fakta bahwa pengambilan sampel darah pendonor dilakukan dengan cara menusukkan jarum pada ujung jari pendonor.

Berbagai penelitian yang telah dilakukan terkait dengan alat ukur $\mathrm{Hb}$ diantaranya adalah (Alfiana dkk., 2019), (Anggraeny, 2010), (Maulana, 2020), (Ningsih dkk., 2019), (Prasetyo, 2019), (Qomaruddin, 2016), (Umar \& Alyah, 2020), (Umar \& Alyah, 2020a), (Umar \& Amin, 2019), dan (Wijaya et al., 2017). Akan tetapi penelitian-penelitian tersebut belum ada yang menggunakan atau tidak berbasis pada aplikasi android. Oleh karena itu, dibutuhkan alternatif teknologi pengukur kadar hemoglobin yang dapat dilakukan dengan mudah, nyaman, murah, dan akurat. Dalam hal ini, tim pengabdian masyarakat menawarkan alat ukur $\mathrm{Hb}$ berbasis aplikasi android yaitu $\mathrm{HbEy}$.

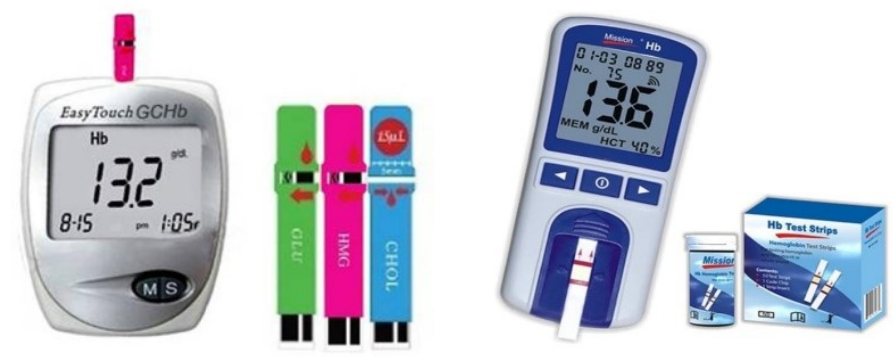

Gambar 1. Jenis alat ukur $\mathrm{Hb}$ yang selama ini digunakan melalui proses pengambilan darah secara invasif

Aktivitas donor darah Unit Transfusi Darah (UTD) PMI Kabupaten Indramayu merupakan aktivitas utama dan berkala. Oleh karena itu, implementasi teknologi kesehatan sangat berpotensi mempermudah kerja dan meningkatkan optimalisasi peran PMI di wilayah Kabupaten Indramayu. Selain itu, sistem teknologi kesehatan yang diterapkan akan mendapat dukungan penyempurnaannya. Kegiatan pengabdian masyarakat ini merupakan salah satu bentuk sumbangsih Telkom University bagi kemajuan masyarakat khususunya masyarakat kabupaten Indramayu dan sekitar, terutama bagi PMI Kabupaten Indramayu di bidang ICT kesehatan. Manfaat kegiatan pengabdian masyarakat ini yaitu sebagai sarana untuk meningkatkan citra institusi pendidikan yang terdepan di bidang ICT, dan sebagai sarana untuk promosi dan bargaining position yang 
strategis di kalangan masyarakat luas dan pihak-pihak pemangku kepentingan yang terkait.

\section{Metode}

Kegiatan pengabdian masyarakat ini menggunakan kombinasi beberapa jenis metode untuk menyelesaikan masalah atau persoalan yang muncul pada mitra. Beberapa kombinasi metode yang digunakan dalam pengabdian masyarakat ini diuraikan sebagai berikut.

- Difusi Ipteks: Ide dan teknologi baru yang dihasilkan oleh dosen yang tergabung dalam tim riset Kelompok Keahlian Pemrosesan Sinyal Informasi (KK PSI) Telkom University disebarkan pada suatu komunitas atau instansi. Proses difusi ipteks berlangsung dengan pola komunikasi berbentuk pengenalan dan pelatihan penggunaan alat ukur hemoglobin non invasif HbEy.

- Pelatihan: a) Tim pengabdian masyarakat melakukan demonstrasi dan mencontohkan penggunaan alat ukur hemoglobin non invasif HbEy, b) Peserta pelatihan yang merupakan para pegawai di PMI Kabupaten Indramayu mempraktekkan cara mengoperasikan alat ukur hemoglobin non invasif $\mathrm{HbEy}$.

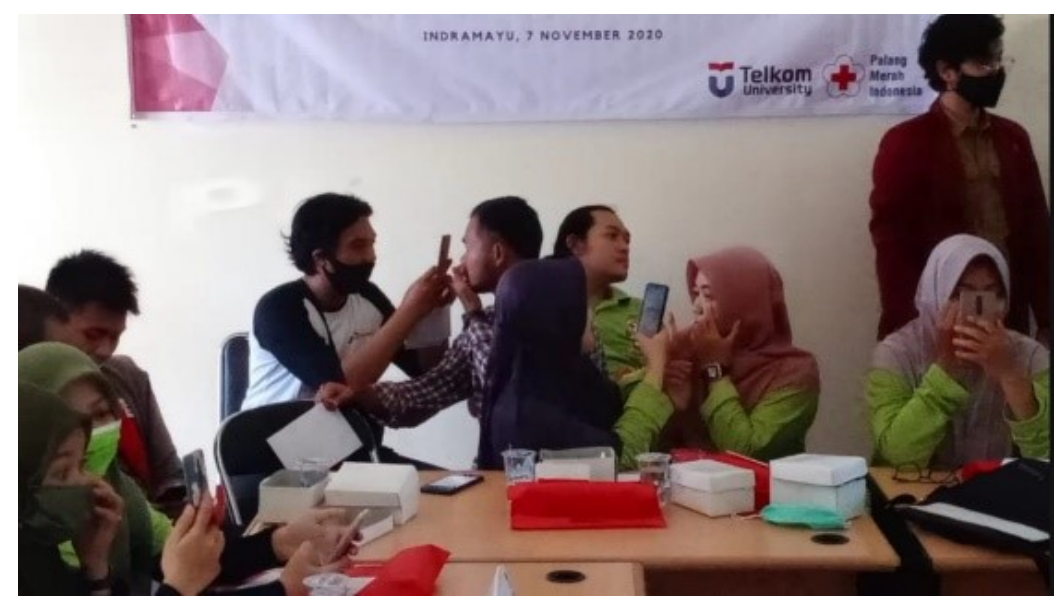

Gambar 2. Praktek penggunaan HbEy oleh peserta

- Substitusi Ipteks: Pengabdian masyarakat ini menawarkan ipteks baru yang lebih modern, murah, nyaman, mudah, dan akurat kepada mitra.

Akurasi pengukuran hemoglobin non-invasif HbEy diperoleh dengan cara membandingkan hasil yang diperoleh menggunakan metode invasif yang selama ini telah digunakan di PMI Kabupaten Indramayu. Dalam hal ini, metode invasif digunakan sebagai base line untuk mengukur tingkat akurasi 
[93] Hilma Fauzi TSP, dkk / To Maega : Jurnal Pengabdian Masyarakat, Vol.4; No.1; Februari 2021

metode non-invasif HbEy. Prosedur penggunaan alat ukur hemoglobin diuraikan sebagai berikut.

\section{A. Mempersiapkan Alat Ukur Hemoglobin Non-Invasif (HbEy).}

1. Peserta pelatihan mendownload di play store dengan nama aplikasi HbEy ( $\mathrm{Hb}$ Calculator) atau menginstal aplikasi HbEy dari file master APK yang diberikan oleh tim pengabdian masyarakat Telkom University.

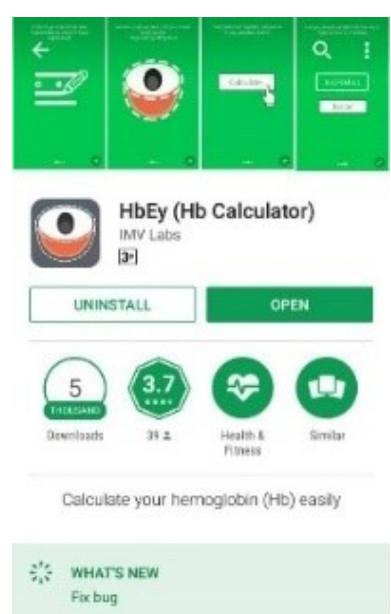

Gambar 3. Tampilan HbEy di play store

2. Peserta pelatihan diperkenalkan menu-menu yang ada pada aplikasi $\mathrm{HbEy}$ (Hb Calculator).

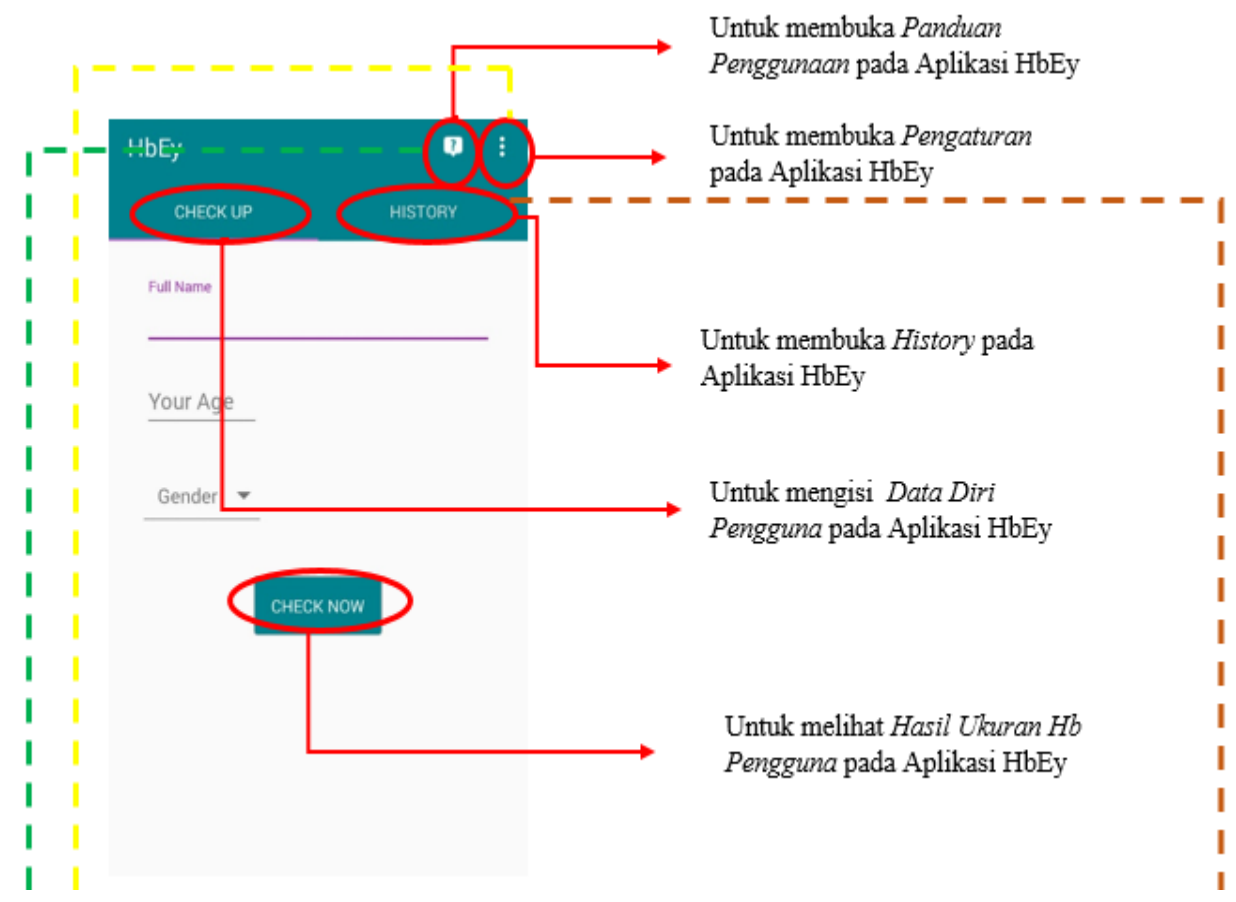

Gambar 4. Menu-menu pada aplikasi HbEy 


\section{B. Proses Pengukuran Kadar Hemoglobin Non Invasif Menggunakan Aplikasi HbEy}

1. Peserta pelatihan memasukkan data pendonor yang akan diukur kadar hemoglobinnya. Data yang dimasukkan meliputi: Nama Lengkap, Umur, dan Jenis Kelamin. Setelah mengisi data pendonor, peserta pelatihan diarahkan untuk menekan tombol CHECK NOW. Tempat memasukkan data seperti ditunjukkan pada Gambar 4

2. Peserta pelatihan mengambil foto kelopak mata bagian dalam (konjungtiva) pendonor dengan cara mensejajarkan dengan garis panduan.

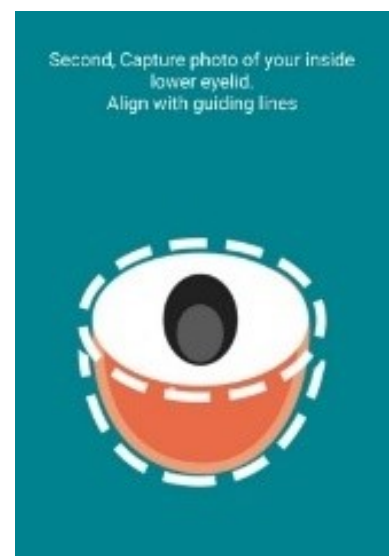

Gambar 5. Garis panduan pengambilan foto konjungtiva

3. Peserta pelatihan memulai pengukuran kadar hemoglobin dengan menekan tombol Calculate.

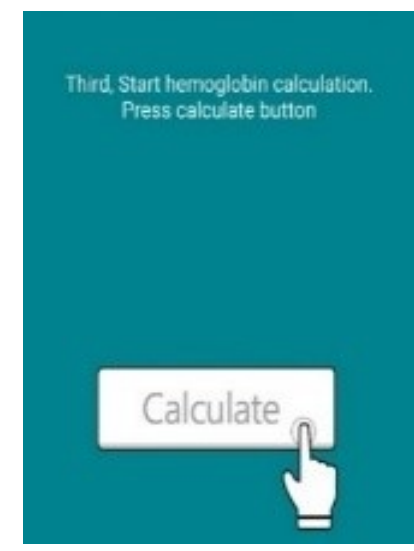

Gambar 6. Tombol Calculate untuk memulai pengukuran $\mathrm{Hb}$

4. Peserta pelatihan menunggu beberapa saat untuk melihat hasilnya. Hasil yang diperoleh berupa keterangan Normal atau Anemia seperti ditunjukkan gambar berikut. 


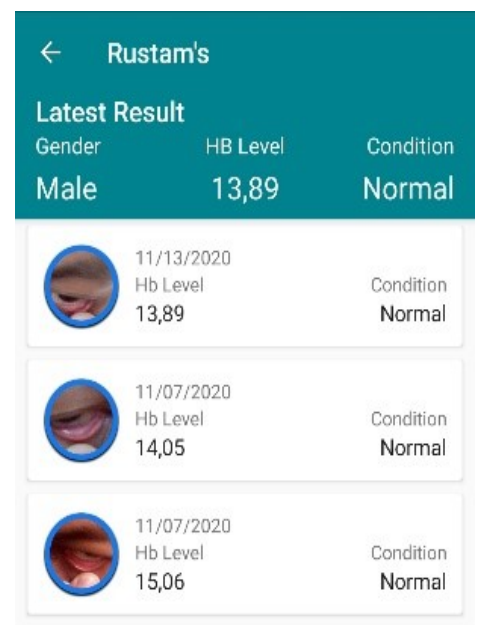

Gambar 7. Hasil pengukuran kadar $\mathrm{Hb}$

Terakhir, kembali ke beranda aplikasi HbEy untuk memindai pendonor yang lain.

\section{Hasil dan Pembahasan}

Pada hari Sabtu, 7 November 2020 telah berlangsung pengabdian masyarakat pelatihan implementasi alat ukur hemoglobin non-invasif (HbEy) di PMI Kabupaten Indramayu dengan jumlah peserta sebanyak 17 orang dari kalangan pegawai/staf PMI Kabupaten Indramayu.

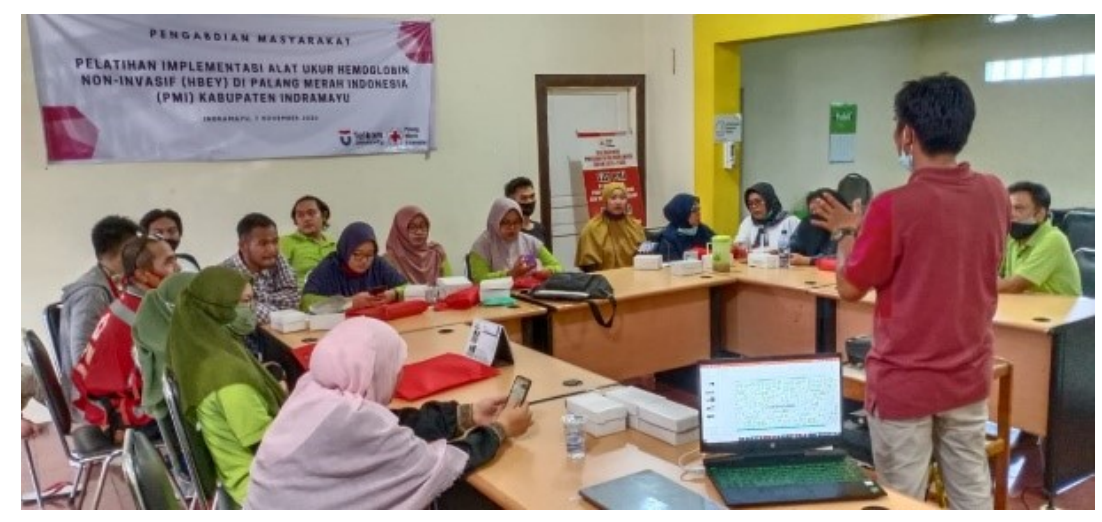

Gambar 8. Suasana pelatihan implementasi alat ukur hemoglobin non-invasif (HbEy)

Pelatihan dimulai dengan presentasi dari tim pengabdian masyarakat Telkom University dengan menguraikan hal yang melatarbelakangi munculnya ide untuk menciptakan alat ukur hemoglobin non-ivasif (HbEy). Inti presentasi tersebut adalah menjelaskan secara detail teknik pengukuran hemoglobin nonivasif menggunakan aplikasi HbEy.

(C)To Maega / Jurnal Pengabdian Masyarakat. This is an open access article under the CC BY-SA 4.0 license (https://creativecommons.org/licenses/by-sa/4.0/). 

2021

Hasil yang diperoleh menunjukkan bahwa peserta telah menginstal aplikasi HbEy di smartphone masing-masing dan telah mampu untuk melakukan pengukuran hemoglobin menggunakan aplikasi HbEy yang berbasis android. Para peserta telah mampu melakukan pengukuran hemoglobin satu sama lain dan juga mampu untuk melakukan pengukuran hemoglobin terhadap diri sendiri. Karena memang HbEy dirancang selain untuk melakukan pengukuran hemoglobin pada orang lain juga diracancang untuk dapat melakukan pengkuran hemoglobin pada diri sendiri.

Pelatihan implementasi alat ukur hemoglobin non-invasif (BbEy) yang berlangsung di kantor PMI Kabupaten Indramayu kemudian dilanjutkan dengan kegiatan donor darah di salah satu kecamatan di Kabupaten Indramayu, tepatnya Kecamatan Tukdana. Di tempat inilah para staf PMI Kabupaten Indramayu yang telah mengikuti pelatihan mempraktekkan secara langsung pengukuran hemoglobin non-invasif menggunakan aplikasi HbEy kepada para pendonor/volunteer yang akan mendonorkan darahnya. Volunteer yang mengikuti kegiatan donor darah di Kecamamatn Tukdana berjumlah 27 orang dengan rincian 21 laki-laki dan 6 orang perempuan.
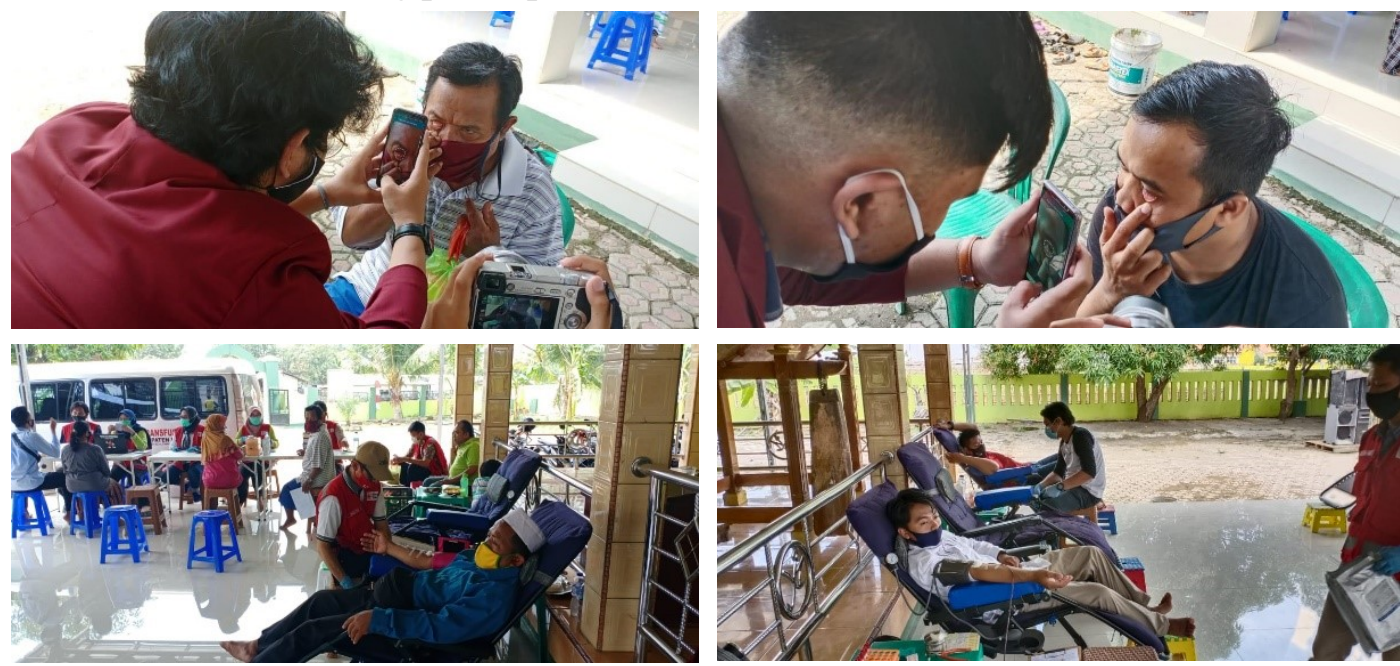

Gambar 9. Praktek penggunaan alat ukur hemoglobin non-invasif (HbEy)

Perbandingan hasil pengukuran hemoglobin antara metode non-invasif (HbEy) dengan metode invasive ditunjukkan pada Gambar 10 berikut. 


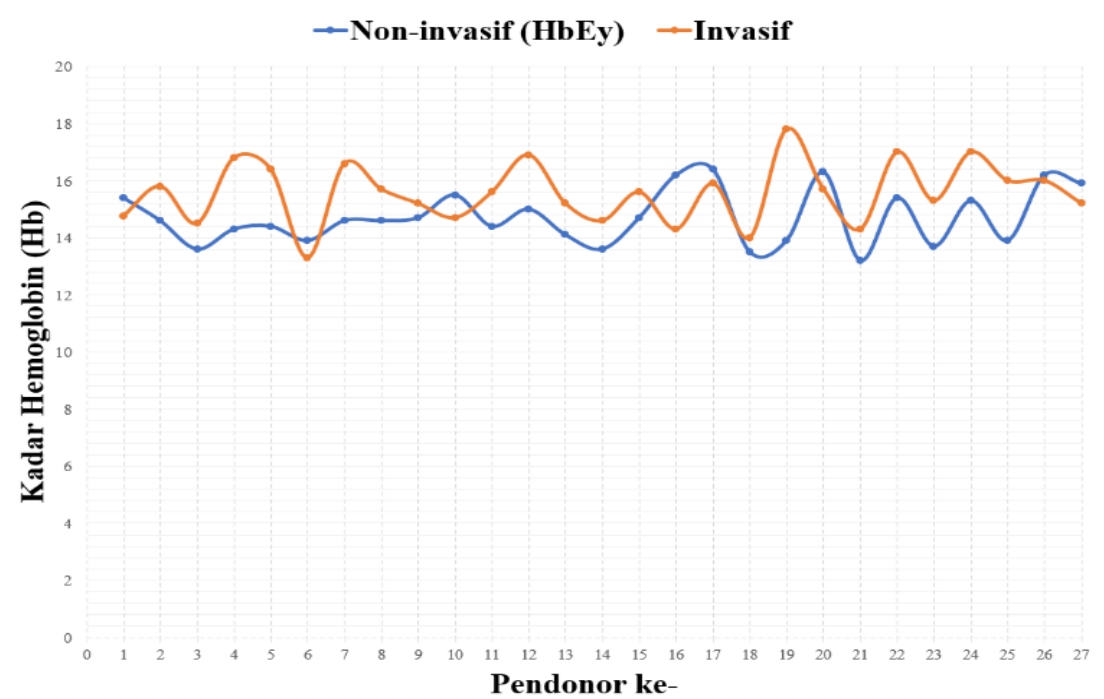

Gambar 10. Perbandingan hasil pengukuran hemoglobin antara metode non-invasif (HbEy) dengan metode invasif

Gambar 10 menunjukkan data hasil perbandingan antara metode non-ivasif (HbEy) dan metode invasif dalam mengukur kadar hemoglobin 27 orang volunteer/pendonor. Kadar hemoglobin normal pada laki-laki adalah 13-16 g/dL, sedangkan pada perempuan adalah 12-14 g/dL (Suciani, 2007). Seseorang dikatakan mengalami kekurangan hemoglobin (anemia) apabila hasil pengukuran hemoglobinnya lebih rendah dari rentang ini. Calon pendonor sebaiknya juga memiliki kadar hemoglobin sekitar 12,5-17 g/dL, dan tidak lebih dari $20 \mathrm{~g} / \mathrm{dL}$ (WHO, 2012). Berdasarkan rentang

Hasil ini menunjukkan adanya selisih kadar hemoglobin yang diperoleh dengan menggunakan metode non-invasif ( $\mathrm{HbEy}$ ) dan metode invasif pada tiap volunteer/pendonor. Hal ini dapat disebabkan oleh teknik pengambilan foto kelopak mata bagian dalam (konjungtiva) yang tidak presisi sehingga aplikasi HbEy tidak mendeteksi dengan tepat tingkat kecerahan konjungtiva pendonor. Selain itu, juga dapat disebabkan oleh tingkat pencahayaan yang bervariasi saat foto konjungtiva diambil sehingga menyebabkan adanya perbedaan dengan hasil pengukuran metode invasif. Namun demikian, dari 27 volunteer yang diukur kadar hemoglobinnya, alat ukur hemoglobin non-invasif (HbEy) mampu untuk menyajikan informasi terkait normal atau tidaknya (anemia) calon pendonor. Berdasarkan Gambar 10. informasi terkait normal atau tidaknya kadar hemoglobin calon pendonor yang diberikan oleh HbEy bersesuaian dengan metode invasif. Dengan kata lain, jika metode invasif memberikan hasil normal maka HbEy juga memberikan hasil normal dan begitu pula sebaliknya. Sehingga aplikasi HbEy dapat menjadi acuan awal untuk mengambil keputusan apakah calon pendonor layak untuk melakukan donor darah atau tidak.

Sebagai langkah tindak lanjut dari program pengabdian masyarakat ini, maka tim pengabdian masyarakat dari Telkom University akan melakukan CTo Maega / Jurnal Pengabdian Masyarakat. This is an open access article under the CC BY-SA 4.0 license (https://creativecommons.org/licenses/by-sa/4.0/). 
perbaikan dan pengembangan pada alat ukur hemoglobin non-invasif (HbEy). Hal ini bertujuan untuk menangani kekurangan dan menambahkan variabel yang diduga memberi pengaruh pada kadar hemoglobin. Tim pengabdian masyarakat Telkom University tetap akan menjalin komunikasi lanjutan dengan PMI Kabupaten Indramayu sebagai kerjasama lanjutan untuk implementasi dari pengembangan aplikasi HbEy. Harapannya, pengembangan yang dilakukan mampu untuk memberikan hasil pengukuran yang presisi dengan akurasi mendekati $100 \%$ jika dibandingkan dengan metode invasif.

\section{Kesimpulan}

Dengan terselenggaranya kegiatan pengabdian masyarakat antara Telkom University dan PMI Kabupaten Indramayu, dapat disimpulkan sebagai berikut. Pertama, aplikasi HbEY dapat menjadi salah satu alternatif alat ukur kadar Hb noninvasif yang dengan mudah, murah, dan nyaman untuk digunakan. Kedua, alat ukur hemoglobin non-invasif ( $\mathrm{HbEy}$ ) mampu untuk menyajikan informasi normal atau tidaknya (anemia) calon pendonor. Sehingga HbEy dapat dijadikan sebagai referensi awal, layak atau tidaknya seorang volunteer/pendonor untuk melakukan donor darah. Ketiga, perlu dilakukan pengembangan aplikasi HbEy untuk perolehan hasil pengukuran kadar $\mathrm{Hb}$ yang lebih presisi dengan pengukuran menggunakan metode invasif.

\section{Ucapan Terimakasih}

Tim pengabdian masyarakat mengucapkan terima kasih kepada Telkom University yang telah mendanai kegiatan pengabdian masyarakat ini sehingga dapat berjalan dengan baik.

\section{Daftar Pustaka}

Alfiana, R. D., Zakaria, H., Shahib, M. N. dan Susanto, H. (2019). Accuracy of Hemoglobin Measurement Using Noninvasive Oxyhemoglobinometer in Pregnant Women at Health Center of Bantul District, Jurnal Ners dan Kebidanan Indonesia, 6(1), 59-64.

Anggraeny, N. H. (2010). Rancang Bangun Alat Ukur Kadar Hemoglobin, Kandungan Oksigen dan Kadar Gula dalam Darah pada Manusia Secara Noninvasive Berbasis Mikrokontroler. Ph.D thesis Department of Physics Universitas Diponegoro.

Maulana, I. (2020). Implementasi Komunikasi Data Nirkabel pada Alat Ukur Kadar Hemoglobin Gelang Non-Invasif di Departemen Fisika IPB

Ningsih, E. W., Fajrin, H. R. dan Fitriyah, A. (2019). Pendeteksi Hemoglobin Noninvasive. Medika Teknika: Jurnal Teknik Elektromedik Indonesia. 1(1), 7-12. 
[99] Hilma Fauzi TSP, dkk / To Maega : Jurnal Pengabdian Masyarakat, Vol.4; No.1; Februari 2021

Prasetyo, D. A. (2019), Rancang Bangun Alat Ukur Denyut Jantung, Saturasi Oksigen dalam Darah dan Hemoglobin dengan Metode Non-Invasive, PhD thesis, Universitas Muhammadiyah Purwokerto.

Qomaruddin, Q. (2016). Pengukuran Kadar Hemoglobin (Hb) Darah Dengan Metode Noninvasif Menggunakan Laser. Instrumentasi. 40(1), 15-19.

Suciani, S. (2007), Kadar Timbal dalam Darah Polisi Lalu Lintas dan Hubungannya dengan Kadar Hemoglobin (Studi pada Polisi Lalu Lintas yang Bertugas di Jalan Raya Kota Semarang), Ph.D thesis, program Pascasarjana Universitas Diponegoro.

Umar, U. dan Alyah, R. (2020): A Real Time Non-Invasive Hemoglobin Monitoring System, dalam Seminar Nasional Hasil Penelitian \& Pengabdian Kepada Masyarakat (SNP2M), 63-68.

Umar, U. dan Alyah, R. (2020a): Pemantauan Hemoglobin Darah dengan NonInvasive Menggunakan Sensor Near Infrared LED IR $940 \mathrm{~nm}$, Jurnal INSTEK (Informatika Sains dan Teknologi), 5(1), 93-102.

Umar, U. dan Amin, I. (2019): Monitoring Kadar Glukosa Darah Non-Invasif Menggunakan Sensor Photoacoutic, Celebes Health Journal, 1(2), 99-111.

WHO. (2012): Blood donor selection: guidelines on assessing donor suitability for blood donation, World Health Organization.

Wijaya, I. R. dkk. (2017), Rancang Bangun Telemonitoring Kadar Hemoglobin dalam Darah Secara Non Invasif Berbasi Internet of Things, PhD thesis, Universitas Airlangga. 